\title{
Depression among women with obstetric fistula, and pelvic organ prolapse in northwest Ethiopia
}

Berihun Megabiaw Zeleke ${ }^{1 *}$, Tadesse Awoke Ayele ${ }^{1}$, Mulatu Adefris Woldetsadik², Telake Azale Bisetegn ${ }^{3}$ and Akilew Awoke Adane ${ }^{1}$

\begin{abstract}
Background: The prevalence of depression is not well studied among women with pelvic floor disorders. Hence, this study aimed to determine the prevalence of depression and its associated factors among women with pelvic floor disorders.

Methods: A cross-sectional study was conducted among 306 women with one or more of the advanced pelvic floor disorders who attended at the gynaecologic outpatient clinic of Gondar university referral hospital in the six months data collection period. Women who complained of urinary or faecal incontinence or protruding mass per vagina were assessed and staged accordingly. Eligible women i.e. those with advanced pelvic organ prolapse or obstetric fistula were included consecutively. A structured questionnaire was used to obtain socio-demographic data and medical histories for all consenting women. Interviews were done by a female midwife nurse. Depression measures were obtained using the Beck's Depression Inventory (BDI) tool administered by the midwife nurse after intensive training. Data were entered into a computer using Epi Info version 3. 5.3, and then exported to SPSS version 20 for analysis. Multiple logistic regressions were fitted and Odds ratios with 95\% confidence intervals were calculated to identify associated factors.
\end{abstract}

Results: Of the 306 women interviewed, 269 had advanced pelvic organ prolapse (stages 3 and 4), 37 had obstetric fistula. All four women (100\%) with both faecal and urinary incontinence, $97.0 \%$ those with urinary incontinence due to obstetric fistula and $67.7 \%$ of those with advanced pelvic organ prolapse (stages 3 and 4 ) had symptoms of depression. Depression was significantly associated with age 50 years or older $(P<0.01)$, marital status $(P<0.05)$, history of divorce $(p<0.01)$, self perception of severe problem $(P<0.05)$, and having stage 3 pelvic organ prolapse $(P<0.01)$.

Conclusion: Women with advanced pelvic organ prolapse, and obstetric fistula had high prevalence of depressive symptoms. A holistic management approach, including mental health care is recommended for women having such severe forms of pelvic floor disorders.

Keywords: Depression, Pelvic organ prolapse, Obstetric fistula, Ethiopia

\section{Background}

Pelvic floor disorders, mainly urinary and faecal incontinence, and pelvic organ prolapse, having closely related aetiologies, are common among women of developing countries [1]. Pelvic organ prolapse (POP) occurs when the pelvic floor no longer supports the proper positioning of the pelvic organs, i.e. the vagina, bladder, rectum or uterus. Symptoms of POP include a feeling of vaginal

\footnotetext{
* Correspondence: beredomega@gmail.com

${ }^{1}$ Epidemiology and Biostatistics department, Institute of Public Health, College of Medicine and Health Sciences, University of Gondar, Gondar, Ethiopia

Full list of author information is available at the end of the article
}

bulging and/or pelvic pressure [1]. Women with obstetric fistula are incontinent of urine, faeces, or both. POP, though not uncommon among rural young women [2], is mostly common among older and multiparous women [3], while obstetric fistula among the very young primiparous [4].

Many women with pelvic floor disorders do not seek medical advice $[3,5,6]$ and this makes determining the incidence of gynecological conditions like prolapse and urinary incontinence very difficult. Such gynaecological conditions can impact on sexual well-being of women $[7,8]$ and subsequently psychological problems. Difficulties arise when studying gynaecological morbidities because of

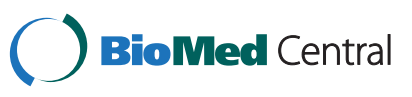


the sensitive and hidden nature of complaints regarding of the genital area [9]. In areas where access to health care is often limited, women usually have to live with the consequences of fistula or prolapse for the rest of their lives [3] which can be a challenge, both physically and emotionally, as the symptoms can disrupt the woman's day-to-day life $[7,10]$.

Failure to control sphincters or having a the uterus outside the vagina, swinging in between thighs, can severely affect a woman's quality of life by limiting her physical, social, psychological and sexual functions and may cause a great deal of discomfort and distress [3,5,11]. Depressive disorders are common, chronic, and a principal source of disability throughout the world especially among women [12,13]. Prevalence of depression is $3-5$ times higher among women with advanced stages of POP compared to normal controls $[14,15]$. The medical and social consequences of obstetric fistula are distressing and can have a profound effect on psychiatric health [16] since depression has been associated with conditions that often accompany disability [17]. Severe forms of gynaecological conditions such as advanced POP and obstetric fistulae having diverse complications, ranging from personal to social, and majorly contribute to disrupted marital relationships or divorce $[7,10]$.

Reflective of most settings of a developing countries, Ethiopia is prone to a number of maternal health related problems like early marriage (median age at first marriage being 14.2 years [18]), grand-multiparity, obstructed labour and its complications, POP [19] and fistula [20]. In Ethiopia so far there is extremely scarce documented literature on the magnitude of depression among patients seeking care for obstetric fistula and/or POP. Hence, this study assessed the prevalence and identified associated factors of depression among patients with obstetric fistula, and advanced POP.

\section{Methods}

A hospital based cross-sectional study was conducted in a four months period (March 1- June 30, 2012) at the gynaecologic clinic of Gondar University Referral Hospital. Women examined and diagnosed by general practitioners as 'cases' of obstetric fistula, or advanced POP were recruited for this study. Prolapse was staged according to the S-POPQ staging system [21]. Fistulae of vesico-vaginal (VVF) and/or recto-vaginal (RVF) which warranted surgery and women who had advanced stages of prolapse i.e. stages 3 and 4. Stage 3 POP represents a stage of prolapse where the leading point descended $>1 \mathrm{~cm}$ outside the hymenal ring, but does not form a complete vaginal vault eversion while stage 4 is complete vaginal vault eversion or procidentia uteri [21].

Data were collected by a midwife nurse who was regularly working at the clinic. The data collector was trained by the research team on methods of data collection. An interview-based questionnaire was used to collect relevant data. The questionnaire was structured into four parts composed of socio-demography, obstetric and gynaecologic history, symptoms about the prolapse, and symptoms of depression.

Symptoms of depression were screened by Beck's Depression Inventory (BDI) tool which is composed of 21 questions, each having $0-3$ scales. The original BDI tool was translated into Amharic (local language) by two experts independently and then approved by the research team. A woman's score was summed up out of 63 points and 21 was taken as cut-off point to label 'symptomatic for depression'.

Data were then entered into a computer using EPI Info Version 3.5.3 and exported to SPSS version 20 for analyzes. Frequency tables and logistic regression tables were used to present results. For risk factor analyses, binary and multivariable logistic regression analyses were performed. All factors with a p-value $<0.2$ in the bivariate logistic regression were entered into the multivariate model. Odds ratios (OR) with 95\% confidence intervals (CI) were calculated to measure associations between the outcome of interest (depression) and explanatory variables. Statistical significance was accepted at the $5 \%$ level $(\mathrm{p}<0.05)$.

Ethical clearance was obtained from the University of Gondar ethical review board and an official letter was written to the hospital administration. The study participants were informed about the aims of the study, the confidentiality of the information to be collected. Data were collected after the woman's verbal consent was obtained.

\section{Results}

\section{Socio-demographic profile of participants}

A total of 306 women with symptomatic pelvic floor disorders (269 POP, 37 VVF of whom 4 had also RVF) were included in this study. Mean age of participants was 50.9 years \pm 13.3 standard deviations (SDs). The aged of participants ranged from 13-75 years and nearly two-third $(63.7 \%)$ aged 50 or older (Table 1). Majority (84.0\%) were rural residents, orthodox Christians (91.8\%) and Amhara by ethnicity (92.6\%). More than one in ten $(12.3 \%)$ of the participant women were currently divorced (Table 1). At an average, women with POP were 23 years older than those with fistula (53.5vs 30.2 years).

The mean ages of participants at their first marriage and first delivery were 14.7 years \pm 2.2 SDs and 17.0 years \pm 1.7 SDs, respectively. More than three quarters (79.7\%) had at least 5 deliveries. The mean duration of time between occurrence of the problem and reporting to the hospital was $3.0 \pm 1.5$ years (ranging between $1-10$ years). Women with POP sought medical care twice much more later than those with fistula (3.2 vs 1.6 years). Twenty two women (7.2\%) had never discussed with anyone about their pelvic 
Table 1 Socio-demographic characteristics of women with advanced pelvic organ prolapse, and fistula at GURH, NORTHWEST Ethiopia $(n=306)$

\begin{tabular}{|c|c|c|c|}
\hline \multicolumn{2}{|l|}{ Characteristic } & \multirow{2}{*}{$\begin{array}{l}\text { Number } \\
34\end{array}$} & \multirow{2}{*}{$\frac{\text { Percent }}{11.1}$} \\
\hline Age in years & $22-34$ & & \\
\hline & $35-49$ & 80 & 26.1 \\
\hline & $50+$ & 192 & 62.7 \\
\hline & Mean \pm SD & \multicolumn{2}{|c|}{$53.5 \pm 11.2$} \\
\hline \multirow[t]{2}{*}{ Residence } & Urban & 45 & 14.7 \\
\hline & Rural & 261 & 85.3 \\
\hline \multirow[t]{2}{*}{ Religion } & Orthodox Christian & 237 & 91.8 \\
\hline & Muslim & 92 & 8.2 \\
\hline \multirow[t]{2}{*}{ Ethnicity } & Amhara & 284 & 92.8 \\
\hline & Tigre & 22 & 7.4 \\
\hline \multirow[t]{3}{*}{ Marital status } & Married & 270 & 88.2 \\
\hline & Divorced & 23 & 7.5 \\
\hline & Widowed & 13 & 4.3 \\
\hline \multirow[t]{2}{*}{ Educational status } & Unable to read and write & 298 & 97.3 \\
\hline & Read and write or primary & 8 & 2.7 \\
\hline \multirow[t]{3}{*}{ Occupational status } & House wife & 282 & 92.2 \\
\hline & Employed (gov't or self) & 11 & 3.6 \\
\hline & Daily Laborer & 13 & 4.2 \\
\hline
\end{tabular}

floor symptoms before visiting the hospital and about three quarters $(77.0 \%)$ of those currently married did not discuss the problem with their husband (Table 2).

\section{Prevalence and associated factors of depression}

A total of 218 women scored 21 or more in the BDI scale, notifying that more than two in three women $(71.2 \%)$ had depressive symptoms by this screening tool. All the four women with both faecal and urinary incontinence, 97.0\% those with urinary incontinence alone, and $67.7 \%$ of women with advanced POP (stages 3 and 4) had symptoms of depression. Depression was by far more common among fistula patients than those with POP (97.3\% vs $67.7 \%$; $<<0.001)$.

Symptoms depression were more prevalent among rural than urban women $(72.2 \% \mathrm{Vs} 62.1 \%)$, divorced than the currently married (91.2\% vs $69.1 \%)$, and among housewives than employed women (72.3\% Vs $45.5 \%)$. It was lower among middle aged (34-49 years) women (60\%), and those with more advanced POP (65.9\% for stage 4 and $76.9 \%$ for stage 3 POP).

In the unadjusted analysis, depression as an outcome was significantly associated with age (50 years or older and those younger than 35 years), woman's level of bother by the problem, and having fistula than POP (Table 3). After adjustment, variables including age 50 years or older (OR 2.06; 95\% CI 1.02,4.19), age at first delivery
Table 2 Gynaecologic and obstetric history of women with advanced POP, fistula at GURH, northwest Ethiopia, 2012

\begin{tabular}{|c|c|c|c|}
\hline Characteristic & & Number & Percent \\
\hline \multirow[t]{3}{*}{ Number of deliveries } & 1 & 16 & 5.3 \\
\hline & $2-4$ & 46 & 15.0 \\
\hline & $5+$ & 244 & 79.7 \\
\hline \multirow[t]{2}{*}{ Age at first marriage } & $<18$ & 288 & 94.1 \\
\hline & $\geq 18$ & 18 & 5.9 \\
\hline \multirow[t]{2}{*}{ Age at first delivery } & $<18$ & 224 & 73.2 \\
\hline & $\geq 18$ & 82 & 26.8 \\
\hline \multirow[t]{2}{*}{ History of divorce } & Yes & 73 & 23.9 \\
\hline & No & 233 & 76.1 \\
\hline \multirow[t]{2}{*}{ Diagnosis } & POP & 269 & 87.9 \\
\hline & Fistula* & 37 & 12.1 \\
\hline \multirow[t]{6}{*}{ Age of occurrence } & $<20$ & 12 & 3.9 \\
\hline & $20-34$ & 39 & 12.7 \\
\hline & $35-49$ & 109 & 35.6 \\
\hline & $50-64$ & 114 & 37.3 \\
\hline & $65+$ & 32 & 10.5 \\
\hline & Mean \pm SD & \multicolumn{2}{|c|}{$48.0 \pm 13.1$} \\
\hline \multirow[t]{4}{*}{ Duration of the problem in years } & 1 & 38 & 12.4 \\
\hline & 2 & 98 & 32.0 \\
\hline & 3 & 68 & 22.2 \\
\hline & $4+$ & 102 & 32.3 \\
\hline
\end{tabular}

*Four had also recto-vaginal fistula.

younger than 18 years (OR 2.03; 95\% CI 1.07,3.87), marital status (OR 3.41; 95\% CI 1.11,10.46), history of divorce (OR 2.25; 95\% CI 1.02,4.95), self perception of severe disease (OR 2.30; 95\% CI 1.04,5.06), and stage 3 POP (OR 2.75; 95\% CI 1.08,7.00) were significantly associated with depression (Table 3 ).

\section{Discussion}

To our knowledge, this is one of the few studies investigating depressive symptoms in women of developing countries with severe forms of pelvic floor disorders. We studied both women with advanced POP, and women with obstetric fistula and found out a $71.2 \%$ prevalence of depression altogether. The prevalence was higher for fistula patients (97.3\%).

A $67.7 \%$ prevalence of depression is by far higher than the $22.0 \%$ prevalence report from the US among women seeking treatment for advanced POP. The US study reported a five times higher prevalence of depression among women with POP compared to those without [14]. Women with advanced forms of POP have decreased body image and overall quality of life [15] compared to their counterparts and this may put them by far for more risks of depression. 
Table 3 Logistic regression analysis of variables with depression among women with advanced pelvic organ prolapse, and obstetric fistula

\begin{tabular}{|c|c|c|c|c|c|c|}
\hline \multirow{2}{*}{ Predictor variable } & & \multicolumn{3}{|c|}{ Depression } & \multirow[t]{2}{*}{ Crude OR $(95 \% \mathrm{Cl})$} & \multirow[t]{2}{*}{ Adjusted OR (95\% Cl) } \\
\hline & & $\overline{\text { Yes }}$ & No & Total & & \\
\hline \multirow[t]{3}{*}{$\overline{\text { Age }}$} & $22-34$ & 28 & 6 & 34 & $3.11(1.16,8.36)^{*}$ & $1.72(.15,2.45)$ \\
\hline & $35-49$ & 48 & 32 & 80 & Reference & Reference \\
\hline & $50+$ & 142 & 50 & 192 & $1.89(1.09,3.29)^{*}$ & $2.06(1.02,4.19)^{*}$ \\
\hline \multirow[t]{2}{*}{ Residence } & Urban & 28 & 17 & 45 & Reference & Reference \\
\hline & Rural & 190 & 71 & 261 & $1.63(.84,3.15)$ & $1.01(.37,2.73)$ \\
\hline \multirow[t]{2}{*}{ Religion } & Christian & 206 & 78 & 284 & Reference & Reference \\
\hline & Muslim & 12 & 10 & 22 & $.45(.19,1.09)$ & $.36(.10,1.31)$ \\
\hline \multirow[t]{2}{*}{ Currently Marital status } & Married & 188 & 82 & 270 & Reference & Reference \\
\hline & Unmarried & 30 & 6 & 36 & $2.18(.87,5.45)$ & $3.41(1.11,10.46)^{*}$ \\
\hline \multirow[t]{2}{*}{ Age at first delivery } & $<18$ & 165 & 59 & 224 & $1.53(.89,2.63)$ & $2.03(1.07,3.87)^{*}$ \\
\hline & $18+$ & 53 & 29 & 82 & Reference & Reference \\
\hline \multirow[t]{2}{*}{ History of divorce } & Yes & 55 & 18 & 73 & $1.32(.72,2.39)$ & $2.25(1.02,4.95)^{*}$ \\
\hline & No & 163 & 70 & 233 & Reference & Reference \\
\hline \multirow[t]{2}{*}{ Diagnosis } & POP & 182 & 87 & 269 & Reference & Reference \\
\hline & Fistula & 36 & 1 & 37 & $17.23(2.32,127.58)^{*}$ & $3.45(0.16,76.90)$ \\
\hline \multirow[t]{3}{*}{ Level of bother } & Mildly & 49 & 38 & 87 & Reference & Reference \\
\hline & Moderately & 86 & 35 & 121 & $1.91(1.07,3.40)^{*}$ & $1.38(.71,2.71)$ \\
\hline & Highly & 83 & 15 & 98 & $4.29(2.14,8.59)^{*}$ & $2.30(1.04,5.06)^{*}$ \\
\hline \multirow[t]{2}{*}{ Stage of POP } & 3 & 30 & 9 & 39 & $1.72(.78,3.80)$ & $2.75(1.08,7.00)^{*}$ \\
\hline & 4 & 153 & 71 & 232 & Reference & Reference \\
\hline
\end{tabular}

*Significant at $\mathrm{P}<0.05$.

A $97.3 \%$ prevalence of depression among women with obstetric fistulae $(100 \%$ for those with both vesico-vaginal and recto-vaginal fistulae) was similar to other reports from Ethiopia (100\%) and a report which screened fistula patients from Ethiopia and Bangladish (97\%) [22,23]. However, this is higher than a study from Kenya which reported a $72.9 \%$ depression symptoms among fistula patients using the Patient Health Questionnaire-9 [16].

Women with fistula were by far more depressed than those with advanced prolapse ( $97.3 \%$ vs $67.7 \%$ ) though the difference was not significant in the multivariate analysis owing to the lower sample size in one of the groups. Since women living with obstetric fistula experience a deep sense of loss that affected them as women and wives, their social networks are breached and marginalized [10] while women with prolapse are not identified easily. Women with fistula are both socially and personally affected. The fact that genital problems like urinary incontinence and POP are hidden and disgusting for women as reported by previous studies in northwest Ethiopia $[8,19]$ may contribute for the high prevalence of depression in this study.

Similar to other studies $[24,25]$, depression was associated with age extremes of the patient. This is in contrary to a report from breast or gynecologic cancer patients [26] where women younger than 50 were more likely depressed. Currently unmarried women were more depressed than married ones. This may probably be due to the fact that being married is having someone caring and most importantly avoids the social stigma associated with being alone or divorced [10]. Sexual intercourse is often affected, thus putting strain on marital relationships and increasing rates of divorce [7]. This is probably one of the reasons for the high prevalence of depression among women with history of divorce in this study.

This study focused only on patients presenting to the gynaecologic outpatient clinic of a teaching referral hospital, and hence the findings cannot be generalized to all women having similar problems. It is unknown whether women with depressive symptoms may be more bothered and present to the hospital, or the other way round i.e. if women with depressive symptoms are less likely to seek care. As depression has been associated with conditions that often accompany disability and in some cases these disabilities may lead to over or underestimating depression $[17,27]$, the true prevalence of depression might be biased.

Furthermore, employing a cross-sectional study design we cannot make conclusions for some variables in regards to whether depressive symptoms are a risk for 
or a consequence. This finding likely only hints at the complex interactions between chronic burdens, psychological variables, risk factors and sequelae. Another most important limitation of this study is the use of the BDI which could have overestimated the prevalence of depression due to its focus on somatic symptoms that normally occur in other physical disorders too. The BDI was not validated in Ethiopia although it is widely used in the country as a screening tool for depression.

\section{Conclusion}

Despite limitations, we believe that the study contributes to the existing literature on depression among low income women with severe pelvic floor disorders seeking care and prompts design of interventions for low-income settings. Routine screening (better if using multiple screening tools including a diagnostic depression screen), evaluation, and treatment are strongly recommended since these women are unlikely to receive treatment or supportive counseling at routine outpatient clinics. Additionally, we recommend further studies with qualitative or mixed designs to explore women's quality of life, and how they experience living with advanced pelvic floor disorders.

\section{Competing interests}

The authors declare that they have no competing interests.

\section{Authors' contributions}

BMZ wrote the proposal, participated in data collection, analyzed the data and drafted the manuscript. TAA, MAW, TAB and AAA approved the proposal with some revisions, participated in data collection, analysis and manuscript writing. All authors read and approved the final manuscript.

\section{Acknowledgements}

The authors are indebted to the Research and Community Service Core Process (RCSCP) of the University of Gondar for financial support. All study participants deserve appreciations for their cooperation.

\section{Author details}

${ }^{1}$ Epidemiology and Biostatistics department, Institute of Public Health, College of Medicine and Health Sciences, University of Gondar, Gondar, Ethiopia. ${ }^{2}$ Department of Gynaecology and Obstetrics, School of Medicine, College of Medicine and Health Sciences, University of Gondar, Gondar, Ethiopia. ${ }^{3}$ Department of Reproductive Health and Health Education, Institute of Public Health, College of Medicine and Health Sciences, University of Gondar, Gondar, Ethiopia.

Received: 27 April 2013 Accepted: 24 September 2013 Published: 26 September 2013

\section{References}

1. Haylen BT, de Ridder D, Freeman RM, Swift SE, Berghmans B, Lee J, Monga A, Petri E, Rizk DE, Sand PK, et al: An International Urogynecological Association (IUGA)/International Continence Society (ICS) joint report on the terminology for female pelvic floor dysfunction. Int Urogynecol J 2010, 21:5-26.

2. Lukman Y: Utero-vaginal prolapse: a rural disability of the young. East Afr Med J 1995, 72:2-9.

3. Walker GJA, Gunasekera P: Pelvic organ prolapse and incontinence in developing countries: review of prevalence and risk factors. Int Urogynecol J 2011, 22:127-135.

4. Muleta M, Rasmussen S, Kiserud T: Obstetric fistula in 14,928 Ethiopian women. Acta Obstetricia et Gynecologica 2010, 89:945-951.

5. Bonetti TR, Erpelding A, Pathak LR: Listening to "felt needs": investigating genital prolapse in western Nepal. Reprod Health Matters 2004, 12:166-175.
6. Wusu-Ansah OK, Opare-Addo HS: Pelvic organ prolapse in rural Ghana. Int J Gynaecol Obstet 2008, 103:121-124.

7. Ahmed S, Holtz S: Social and economic consequences of obstetric fistula: life changed forever? Int J Gynecol Obstet 2007, 99(Suppl 1):S10-S15.

8. Gjerde JL, Rortveit G, Muleta M, Blystad A: Silently waiting to heal: experiences among women living with urinary incontinence in northwest Ethiopia. Int Urogynecol J 2013, 24(6):953-958.

9. Tehrani FR, Hashemi S, Simbar M, Shiva N: Screening of the pelvic organ prolapse without a physical examination; a community based study. BMC Womens Health 2011, 11(48). doi:10.1186/1472-6874-11-48.

10. Mselle LT, Moland KM, Evjen-Olsen B, Mvungi A, Kohi TW: "I am nothing": experiences of loss among women suffering from severe birth injuries in Tanzania. BMC Womens Health 2011, 11(49). doi:10.1186/1472-6874-11-49.

11. Ravindran T, Savitri R, Bhavani A: Women's experiences of utero-vaginal prolapse: a qualitative study from Tamil Nadu, India. In Safe motherhood initiatives:critical issues. Edited by Berer M, Sundari T. Oxford: Blackwell Science; 1999:166-172.

12. Ustun T, Ayuso-Mateos J, Chatterji S, Mathers C, Murray C: Global burden of depressive disorders in the year 2000. Br J Psychiatry 2004, 184:386-392.

13. Patel V, Abas M, Broadhead J, Todd C, Reeler A: Depression in developing countries:lessons from Zimbabwe. BMJ 2001, 322(7284):482-484.

14. Ghetti C, Lowder JL, Ellison R, Krohn MA, Moalli P: Depressive symptoms in women seeking surgery for pelvic organ prolapse. Int Urogynecol J Pelvic Floor Dysfunct 2010, 21(7):855-860.

15. Jelovsek JE, Barber MD: Women seeking treatment for advanced pelvic organ prolapse have decreased body image and quality of life. Am J Obstet Gynecol 2006, 194:1455-1461.

16. Weston K, Mutiso S, Mwangi JW, Qureshi Z, Beard J, Venkat P: Depression among women with obstetric fistula in Kenya. Int J Gynecol Obstet 2011, 115:31-33.

17. Nosek MA, Hughes RB: Psychosocial issues of women with physical disabilities: the continuing gender debate. Rehabil Couns Bull 2003, 46(4):224-233.

18. CSA, ICF International: Ethiopia Demographic and Health Survey 2011. Addis Ababa, Ethiopia and Calverton, Maryland, USA: Central Statistical Agency and ICF International; 2012

19. Megabiaw B, Adefris M, Rortveit G, Degu G, Muleta M, Blystad A, Kiserud T, Melese T, Kebede Y: Pelvic floor disorders among women in Dabat district, northwest Ethiopia: a pilot study. Int Urogynecol J 2013, 24:1135-1143.

20. Muleta M, Fantahun M, Tafesse B, Hamlin EC, Kennedy RC: Obstetric fistula in rural Ethiopia. East Afr Med J 2007, 84:525-533.

21. Manonai J, Mouritsen L, Palma P, Contreras-Ortiz O, Korte JE, Swift S: The inter-system association between the simplified pelvic organ prolapse quantification system (S-POP) and the standard pelvic organ prolapse quantification system (POPQ) in describing pelvic organ prolapse. Int Urogynecol J 2011, 22(3):347-352.

22. Browning A, Fentahun W, Gon JT: The impact of surgical treatment on the mental health of women with obstetric fistula. BJOG 2007, 114(11):1439-1441.

23. Goh J, Sloane K, Krause H, Browning A, Akhter S: Mental health screening in women with genital tract fistulae. BJOG 2005, 112(9):1328-1330.

24. Hendrix SL, Clark A, Nygaard I, Aragaki A, Barnabei V, McTiernan A: Pelvic organ prolapse in the Women's health initiative: gravity and gravidity. Am J Obstet Gynecol 2002, 186:1160-1166.

25. Paganini CBL, Minanni CA, Ferreira AB, Eras AE, Chekin G, Motta BR, Santos $\mathrm{R}$, Rodrigues FFO: Depressive disorder: subdiagnosis in woman with gynecological neoplasms. Applied Cancer Res 2009, 29(2):74-82.

26. Ell K, Sanchez K, Vourlekis B, Lee P-J, Dwight-Johnson M, Lagomasino I, Muderspach L, Russell C: Depression, correlates of depression, and receipt of depression care among Low-income women with breast or gynecologic cancer. Clin Oncol 2005, 23(13):3052-3060.

27. Aikens JE, RM A, Pliskin NH, Fischer JS, Wiebe JS, McCracken LM, et al: Assessing depressive symptoms in multiple sclerosis: is it necessary to omit items from the original beck depression inventory? J Behav Med 1999, 22:127-142.

doi:10.1186/1471-244X-13-236

Cite this article as: Zeleke et al:: Depression among women with

obstetric fistula, and pelvic organ prolapse in northwest Ethiopia. BMC Psychiatry 2013 13:236. 